\title{
Who May Geoengineer: PATRICK Global Domination, TAYLOR SMITH Revolution, and Solar Radiation Management
}

\begin{abstract}
This paper uses a novel account of non-ideal political action that can justify radical responses to severe climate injustice, including and especially deliberate attempts to engineer the climate system in order reflect sunlight into space and cooling the planet. In particular, it discusses the question of what those suffering from climate injustice may do in order to secure their fundamental rights and interests in the face of severe climate change impacts. Using the example of risky geoengineering strategies such as sulfate aerosol injections, I argue that peoples that are innocently subject to severely negative climate change impacts may have a special permission to engage in large-scale yet risky climate interventions to prevent them. Furthermore, this can be true even if those interventions wrongly harm innocent people.
\end{abstract}

Keywords: climate change; climate engineering: solar radiation management; revolution; non-ideal justice; global justice.

\section{Introduction}

'A social movement that only moves people is merely a revolt. A movement that changes both people and institutions is a revolution.' (Martin Luther King Jr, cited in Carson, 2001).

'The first lesson a revolutionary must learn is that he is a doomed man' (Huey Long, 1973: 3).

The consequences of the anthropogenic climate change will be severe, even if we take (as of yet, unforthcoming) dramatic and rapid steps to lower our carbon emissions and adapt to potential climate impacts. What's more, these consequences will not be distributed equitably or according to who is responsible for or benefits most from the greenhouse gas emissions causing those negative impacts (Vanderheiden, 2008; Weisbach and Posner, 2013, $5^{\text {th }}$ IPCC Report). The people who will suffer the worst impacts of climate change will be those who are least responsible for it occurring (Althor et al., 2016). Some of this inequality is the result of luck; many (though by no means all) high emitting countries are located in ecosystems that are less vulnerable and more resilient to climate change impacts. However, most of this inequality is a consequence of the global political, economic, and social order. High emitting countries are richer than low emitting countries, and richer countries are more able to adapt to the environmental impacts of climate change. Further, a history 
of colonialism and a global order that takes the interests of rich and powerful countries most seriously has undermined the ability of low-emitting countries to develop the kinds of institutions and wealth that would enable an effective response to negative climate change impacts. Rich and powerful nations have created a global order by which they dominate the poor and the marginalized, operating in a way that is unaccountable to the low-emitting, vulnerable states that will suffer the worst consequences of climate change (Bloomfeld, 2015; Smith, 2015).

Much of the discussion of the ethics of geoengineering operates independently from these facts about how the powerful relate to the powerless. That is, most attempts to either justify or object to the research and deployment of geoengineering responses to climate change either adopt the perspective of high-emitting, powerful states or a global perspective, implicitly assuming that it makes no difference who deploys them. ${ }^{1}$ The argument of this paper is that these facts do make a difference. Vulnerable, low-emitting nations have a more easily justified permission-based on the unjust relations that currently obtain between those nations and powerful, high-emitting actors-to deploy dangerous geoengineering strategies in response to climate change.

Rather than understand these risky deployments as acts of self-defense or civil disobedience, I argue that they would represent a kind of geopolitical revolution; a conscientious rejection of the political relations that currently obtain between the vulnerable, low-emitting states and the powerful, high-emitting ones. This 'revolutionary geoengineering' gives rise to special permissions and justificatory demands. The purpose of this paper is to lay out those demands and suggest how a coalition of vulnerable states could meet them. ${ }^{2}$

\section{A Brief Precis on Geoengineering}

Anthropogenic climate change is caused by the intersection of two factors: how much of the sun's energy strikes the earth and how much of that energy is absorbed by the earth's atmosphere. The emission of greenhouse gas, most importantly but not solely carbon dioxide, alters the makeup of the atmosphere so that a greater percentage of the sun's energy is absorbed, leading to a rise in temperature. The standard responses to climate change include mitigationwhereby we decrease our emissions of greenhouse gases in order to reduce potential climate impacts-and adaptation, where we work to create more

1 This is not meant as a criticism. Many of these articles are excellent. Gardiner (2012) is an exception to this trend of neglect.

2 In some ways, this paper serves as a case study that will allow us to examine the bases for Buchanan's (2013) and Caney's (2015) accounts of resistance to global injustice. 
resilient social and economic systems so that they take less damage from the climate impacts that occur.

Solar radiation management (SRM), by contrast, purports to block, prevent, or soften climate impacts through large-scale interventions into the climate system by increasing the reflectivity - or albedo - of the planet. Since more energy is reflected into space, global temperatures will experience a downward pressure. Many SRM proposals are essentially harmless - such as painting roads and rooftops white - but will contribute very little towards reducing potential climate impacts. The most significant and important SRM technique under serious consideration is sulfate aerosol injections (SAIs). ${ }^{3}$ SAIs increase the reflectivity of the planet through the insertion of tiny sulfate particles into the upper atmosphere. Based on models derived from the cooling effects of volcanic eruptions, it is believed that these injections will reflect a small, marginal percentage of the sun's energy back into space and thereby cool the planet. The intervention is scalar: small injections of sulfates will cool the planet a small amount and larger injections will reflect more sunlight and cool the planet to a greater extent.

SAIs are being considered in part because they have dramatic apparent benefits in terms of cost and speed. Generally speaking, accomplishing a similar amount of cooling with mitigation measures will likely be orders of magnitude more expensive than with SAIs (Keith, 2013). New, specially engineered particles may lower the cost of SRM to an even greater extent. ${ }^{4}$ SAIs are potentially so cheap that rich private foundations, large multinational corporations, medium size countries, or a coalition of small countries all have the financial resources to support deployment. Beyond cost, and importantly for vulnerable nations, SAIs have the potential to reverse or slow global warming quickly. Even under optimistic scenarios, the climate system responds too slowly and greenhouse gas emissions remain in the atmosphere for too long for mitigation to prevent all future climate change impacts. Yet, SAIs have the potential to cool the planet (or slow the rate of warming) within months of deployment. So, if there is a specific impact that needs to be avoided quickly in the near future - such as the melting of permafrost or sea level rise that will swallow the Maldives - SAIs are the only mechanism available.

In spite of these advantages, SAIs have been subject to considerable and well-deserved skepticism (Tuana et al., 2011). First, it is possible that SAI

3 This can be a bit of a misnomer as it is likely that sulfates will not be used in whatever SRM strategy we envision. This is why I have argued (Smith 2018) that we should use a more general term: reflective aerosol injections. To avoid confusion, I will use the standard nomenclature in this paper.

4 For example, these particles might be cheaper, more reflective, or remain in the atmosphere longer. 
deployment would undermine the political will to make the difficult sacrifices required by a mitigation plus adaptation strategy (Morrow, 2014). Second, SAIs do not - even in principle - deal with some of the most severe impacts of greenhouse gas emissions like ocean acidification, which would require additional measures. Third, SAI deployment without mitigation would generate a problematic termination shock where we would see rapid temperature increase if deployment stopped (Corner and Pidgeon, 2010). This, some have argued, reflects and exacerbates a problematically dominating or exploitative relationship between the present and the future (Smith, 2012). Fourth, SAI will probably generate unintended negative environmental effects, including and especially the disruption of precipitation patterns around the world that would undermine food and water security - at least potentially-for millions. Finally, the very cheapness and ease of deployment leads to a governance problem as the possibility of unilateral deployment by a single or small set of actors could lead to conflict.

Yet, a strict comparison of the costs and benefits of SAI will be morally incomplete. Climate change is a problem generated by a distinct subset of individuals who have and will continue to benefit from their emissions behavior. So, the deployment of SAI by rich and powerful countries seems to be a particularly egregious kind of moral corruption (Gardiner, 2011). The high emitters generate a serious problem while simultaneously benefitting and, in order to avoid distributing some of those benefits to at-risk people who are not responsible for the serious problem, they engage in a technocratic solution that will also risk another serious harm to innocent parties. Since SAIs will benefit the high emitters-in comparison to a world where they satisfy their moral obligations with adaptation and mitigation-any claim to deploy geoengineering 'on behalf' of those who are vulnerable to climate change impacts seems morally suspect. Moreover, if, as I argue below, high emitters politically dominate low emitters, then the claim becomes even more suspect: it compounds domination if we allow dominators to speak for the dominated.

\section{Self-Defense and Geoengineering}

Consider Oceania:

ISLAND: Oceania, a moderately wealthy island nation, sees its existence threatened by the rising sea levels caused by global warming. Sea walls will be inadequate or prohibitively expensive, especially given the short time table. While there is an international regime to deal with climate change, it will operate too slowly to prevent the relevant impacts. So, Oceania takes advantage of contemporary 
research, builds a designed particle that will not clump or fall quickly from the sky, and deploys it into the atmosphere in order to slow the rate of temperature increase. The geoengineering, combined with the international regime and adaptation measures, will prevent the island from being swamped by sea level rise, saving it from destruction.

This looks like an act of self-defense. ${ }^{5}$ Suppose that some other nation dammed or released a river that flowed into another state, threatening to make the latter country uninhabitable. Few would deny that the flooded state has a right to engage in military action to prevent its destruction. According to just war theory, a right of national self-defense against aggression is designed to protect two key values for political communities: political autonomy and territorial integrity (Walzer, 2000). Sea level rise in ISLAND threatens both values. Oceania is being forced to consider significant changes to its polity and risks the complete loss of its territory as a consequence of the intentional policy of other global actors. ${ }^{6}$ The consequences of the flooding will be severe, destroying the political community of Oceania. Intuitively we would accept military actions in cases much less severe - such as when a state's sovereignty or territory is only partially violated - than the climate change threat facing Oceania. There is, then, some prima facie plausibility to the claim that Oceania could engage in risky and normally impermissible behavior in order to protect its territory and autonomy in much the same way that a nation threatened with aggression can engage in a risky action like military action that would normally be impermissible.

However, there are some reasons to be skeptical. While some have argued that Oceania's geoengineering would violate certain constraints of jus in bello, these arguments have relied upon contingent facts about the consequences of SRM (Gardiner, 2012). But I wish to argue that geoengineering is not appropriately understood as an act of self-defense at all. There are two primary problems with the self-defense conceptualization. First, a claim of self-defense relies on the

5 I set aside the familiar framing that we ought to geoengineer as a response to a 'climate emergency' for three reasons. First, the dangers and problems of the 'emergency framing' have been analyzed in the literature to a much greater extent than these other justifications (Sillman et al., 2015; Gardiner, 2011) Second, it is not clear that emergencies would confer a special permission on those subject to global oppression to geoengineer even if the framing was persuasive. Third, 'supreme emergencies' normally obtain once normal rights to self-defense and their constraints are in abeyance, so they would fall under the analysis I provide of revolution. This section, however, asks whether normally functioning self-defense rights provide OCEANIA with a permission to geoengineer.

6 I am not suggesting that high emitters are aiming at the destruction of Oceania, but they are acting intentionally and with the knowledge that their actions will have the consequences they do. 
idea that the aggressive action is unjustified. ${ }^{7}$ While a right to unilateral selfdefense is used to protect the autonomy and integrity of a state, that autonomy and integrity has limits and a state may not exercise a right to self-defense if the aggressive action is justified. For example, a person is not permitted to engage in self-defense against a lawful and well-justified arrest warrant. Or similarly, one may or may not accept Jeff McMahan's claim about the equality of combatants, but it is clearly true that Nazi Germany had no right to 'defend itself' against the Allied invasion of Normandy (McMahan, 2004). So, if the aggression is justified, then the claim that the defenders can engage in risky action to stop the aggression is undermined.

In ISLAND, the 'aggression' that Oceania will defend itself against is much more complicated and nuanced than a normal military attack or even the analogous flooding caused by the deliberate act of aggression. Rather, the flooding of Oceania is caused by an aggregate of many, individually harmless actions. And different sets of people have differential claims to be able to emit (Shue, 1993). So, the destruction of Oceania results from a combination of emissions behaviors, some of which are obviously unjustified. Yet, a growing percentage of greenhouse gas is emitted by individuals in developing countries in order to escape dire poverty. It is not implausible to think that these emissions are morally justified, representing a requirement for living a minimally decent life. As a consequence, some significant subset - though by no means all or most of the emissions that threaten Oceania are justified by reference to moral claims that seem to be at least as important as those that would undergird Oceania's claim to geoengineer in self-defense. Insofar as the threat to Oceania is at least partly a product of people acting in ways to which they are entitled, a risky and unilateral response - as opposed to appealing to some mechanism of political adjudication between legitimate claims - seems less justified.

7 Oceanian geoengineers could plea necessity, arguing that - like the hiker that must break into a cabin to save himself in a blizzard - it is permissible to violate the entitlements of others for self-preservation. This response may dodge some of the objections I describe below because it does not rely upon the claim that the threat of sea level rise represents unjust aggression. The entitlements being violated may be perfectly legitimate. Yet, this strategy has serious problems. First, arguments from necessity normally depend upon the violated entitlement being a less urgent or important interest than the interest being protected: the life of the hiker versus the property rights of the cabin owner. When the interests are equivalent - such as in the famous case of $R v$. Dudley and Stephens where two sailors cannibalize a sick cabin boy to save themselves - our intuitions are not clear. Similarly, other cases of necessity such as a case where one must kill one conjoined twin to save the other - occur when the violation of an entitlement is a dominant strategy: if we do not kill one twin then both will die anyway. Neither condition applies in the case of geoengineering. The interests risked by solar geoengineering are as important as those that will be saved and some will likely suffer and die from solar geoengineering that would not have had Oceania foregone SAIs. Of course, Oceania may argue that the number of people who will benefit from geoengineering will be so large as to activate a claim of necessity, but this is likely only to be true if we include those who do not live in Oceania. So, Oceania would be claiming to be able to unilaterally violate the basic rights of others in the name of the interests of people outside their jurisdiction. This moves us far past the usual claims of necessity. I thank an anonymous reviewer for pushing me on this point. 
One might try to rescue the claim to justified self-defense by appealing to the fact that morally justified emissions make up a comparatively small though growing part of the threat. It is only in combination with the unjustified emissions of high emitter nations that the problem becomes unmanageable. There are two problems. First, it does not follow from the fact that an individual is emitting at an unjustifiable level that they thereby expose themselves to harm in response. It could be true that there are unavoidable path-dependent dynamics in emissions behavior where individuals blamelessly cannot reduce their (unjustifiably high) level of emissions to a morally appropriate level without undermining the legitimate entitlements they or others possess. For example, it might be the case that decarbonizing at a rate that would be rapid enough to save Oceania might undermine a carbon intensive economy to such a degree that blameless individuals in that economy - such as the poor, the marginalized, or the young - might suffer catastrophic welfare losses. This does not change the fact that a particular carbon intensive economy unfairly exploits the planet's ability to safely absorb carbon, but it does generate a nonideal justification for failing to de-carbonize as rapidly as would be necessary to save Oceania. Second, geoengineering is unlike a defensive military response in important ways; its risks cannot be targeted or directed at only those threats that are morally unjustified. In the case of a military assault, one can choose to direct a defensive response against only those who were engaged in unjustified aggression. However, the threat to Oceania is the result of the aggregate of both unjustified and justified emissions; the threats cannot be differentiated as they are jointly necessary. And even if they were distinguishable in principle, SAIs are not discriminant.

The problem is, in fact, much worse for geoengineering than it being merely undirected. Rather, the negative, unintended consequences of geoengineering will likely fall - to a greatly disproportional extent - on low-emitting and developing nations (Tuana et al., 2014). This is both due to ecology and to social structure. It is an unfortunate fact of the global climate system that the expected precipitation disruption caused by SAIs will likely be concentrated in the global south, especially Africa and Asia. Needless to say, this is where the bulk of morally necessary 'subsistence' emissions can be found. Furthermore, the social facts that create the asymmetrical distribution of climate change impacts-high emitting countries are better able to adapt to environmental change due to their greater wealth-apply equally to the negative impacts of SAIs deployment. Wealthy, high emitting countries will be able to respond and adapt to potential precipitation disruptions and avoid the water and food insecurity that will afflict less developed states. The consequences are perverse: 
in order to respond to an unjust threat generated by climate change, Oceania will 'defend itself' by inflicting severe negative effects on the subset of the global population that most justifiably emits greenhouse gas.

I have argued elsewhere (Smith, 2014) that geoengineering represents a redirection of the threat of climate change. It is not merely that one threat is eliminated and a merely contingently connected negative side effect is generated; the negative side effects, the initial threat, and the response are all closely connected. And this matters for our evaluation of geoengineering as a defensive response. If the negative consequences of SAIs are merely a side effect of the action, then we might be able to use the Doctrine of Double Effect to justify the action. If we do apply the doctrine, then the key moral question is whether the harm caused by geoengineering is disproportional to the benefits that Oceania experiences. That will be a complicated and uncertain empirical question, but it is not impossible that some version of SAIs will be proportional. However, if the negative impacts of geoengineering represent a redirection of climate change impacts, then the moral evaluation is both simpler and more principled. If I am being threatened by a murderous gangster, perhaps I can fire at him in self-defense, knowing that I might harm other people. Yet, I cannot leave a note that tricks the gangster into attacking someone else or use a disguise to convince him that someone else has my identity, knowing that that innocent person will be murdered. In other words, I cannot redirect a threat onto an innocent even if a similarly risky strategy that was not a redirection would be justified by the Doctrine of Double Effect. It is important to realize that redirection is not a matter of the intentions of the redirector but is rather a test of how essential the consequences are to the action. I might intend only to send the murderer to another apartment, but this intention fails to justify my action because-intention or not-the consequences are too 'close' to the action when I redirect a threat towards someone else. ${ }^{8}$ Some actions too essentially involve imposing risks upon or harming other people for the Doctrine of Double Effect to function properly and redirection is one way, but perhaps not the only way, an action can be too close to its consequences. And that is precisely what Oceania's action amounts to; a redirection of the threat of climate change

8 In this sense, a redirection can be like the famous example where one merely intends to place John the Baptists' head on a platter but merely foresees that this will result in death. Even if one actually had the intention, it would not matter as the foreseen consequences are too close to the intended. A reviewer suggested that this account makes it impermissible to flip the switch in the Trolley Problem. I would suggest that flipping the switch is permissible in part because it is an innocent third party making the decision. SAIs would fit the following trolley scenario much more closely: a deeply negligent conductor generates a serious threat, the conductor refuses to sacrifice to block the threat, and a person on the tracks directs the train towards others to save themselves. I suspect our intuitions are not obvious in this case and that following the ethics of revolution would make it much more likely that we would accept the potential victim's decision to redirect. I thank an anonymous reviewer for pushing me to be clearer on this as well as Brian Berkey for his discussions of trolley case. 
towards innocent people. Therefore, SAIs represent an intrinsically problematic defensive response to the threat facing Oceania.

There are several features of Oceania's situation that I want to emphasize. First, unlike an obvious case of imperial conquest or aggression, the threat that Oceania faces is in part produced by individuals reasonably exercising at least seemingly justified entitlements to development and, even in the case of high emitters, agents attempting to protect important and valuable interests. Second, we should understand all agents in the example-those attempting to develop their economies, those protecting vital interests in decarbonizing and developed economies, and those attempting to protect Oceania-have found themselves in a deeply non-ideal situation where only second-best responses, if that, are available. As Jamieson (2005) points out, the time when climate change impacts could have been cheaply and easily avoided is past, the protection and satisfaction of everyone's reasonable and legitimate interests may not all be compossible.

\section{Global Domination and Climate Change}

Geoengineering is not merely a response to a difficult and non-ideal natural phenomenon; climate change has been constructed by an unjust global order. I have argued that climate change - and climate change governance by the global order - are characterized by especially deep relations of domination (Smith 2019, 2015). I will not rehearse the full argument here, but I will offer some prima facie reasons for accepting the claim that the political relations between high emitters and the low emitters like Oceania are deeply inequitable and inequitable in a politically problematic fashion.

I treat domination as an intrinsically normative concept that provides the content for a general, natural duty of justice. That is, the fact that someone is dominated, regardless of whether one is doing the dominating, generates at least a pro tanto reason to act. However, the obligation to prevent or stop domination may result in quite different principles depending on the relational or institutional context. An agent (i.e., the dominus) dominates another (the subject) when the dominus exercises arbitrary superior power over the subject. Putting all of these claims together, we have a duty of justice to ensure that political relations are non-dominating by either placing people in positions of equal power or by ensuring that all unequal power is exercised in a nonarbitrary fashion. ${ }^{9}$

Before proceeding, it is important to spend some time considering both the 'superior power' and the 'arbitrariness' requirements. The key notion is that an

9 This account of domination is meant to be agnostic between accounts of freedom that are neo-republican (Pettit, 1997) and Kantian (Ripstein, 2009) in nature. 
agent must have power over an agent as a necessary condition for domination, which is a comparative concept. Knowing the absolute power of an agent will not be directly relevant to judgments of domination. Very powerful agents understood in terms of their ability to manipulate the world - might nonetheless be dominated by even more powerful agents. Conversely, weak agents might be free of domination if there are features of the world, such as geographic isolation or inaccessibility, that prevent powerful agents from exercising power over them. Another key element of superior power is its social character. Take the paradigmatic case of a dominating agent: the slave-owner. Do slave-owners possess superior power over their slaves because of their natural endowments? Very rarely, and such domination is normally unstable. Much more plausible is the claim that slave-owners possess superior power in virtue of their position within a complex matrix of social, economic, and political relations that gives them the ability to control the lives of their slaves. Slave-owners deploy a diversity of mechanisms: the threat of force by armed overseers and militias, legal entitlements to the means of productive capital, rational incentives to cooperation, dense networks of relationships between similarly positioned slave-owners, and the inculcation of social norms of appropriate behavior and loyalty all play an important role in allowing slave-owners to regulate the lives of their slaves in a stable fashion.

But superior social power over another is not necessarily domination. After all, officials in a legitimate democracy often exercise superior power over their constituents but we nonetheless think this is quite different - in terms of justice - from the political relations that obtain between dictators or slave-owners and their respective subjects. Domination only occurs when the exercise of that superior power is arbitrary. Yet, it is important to see that the requirement of non-arbitrariness - thus making superior power consistent with the subject's claim to be free of domination - is more demanding than simply the requirement that those who exercise power do so 'for a good reason.' Of course, nonarbitrariness is sometimes understood - in other contexts - as a lack of caprice; so if I have a good reason for doing something, I am not acting arbitrarily. This conception of arbitrariness is too weak to undergird the conception of justice as non-domination I defend. Rather, arbitrariness is a function of the social context whereby the individual with superior power can act unaccountably, free from contestation, or unconstrained from mutually agreed upon public rules or from the demand that the power be exercised to serve the common good. So, a benevolent dictator - who generally followed the substantive demands of distributive justice with her exercises of power - would be acting non-arbitrarily on the weaker conception (she is, after all, reliably following a 
substantively correct set of principles) but she would be acting arbitrarily on the more demanding conception I have sketched. The reason for this is that - as a dictator with absolute power - it is importantly up to her whether she follows those principles; there is no set of institutions or broader social structures that pressures or ensures that she will be accountable to her subjects or act according to the general will of her fellow citizens. On the other hand, a just liberal democracy or democratic socialist state may exercise superior power non-arbitrarily if it possesses a set of institutions-the social welfare state, the rule of law, a written constitution with counter-majoritarian protections for basic liberties, and democracy - that hold the powerful accountable to the weak.

Now I am in the position to, albeit briefly, show why high emitters dominate low-emitters in the global order. First, high emitters are fundamentally less vulnerable to theimpacts of climate change while being essential to any mitigation suite designed to protect low-emitters. As a consequence, high emitters have greater bargaining power in international negotiations: low-emitters, especially the very lowest emitters, are essentially irrelevant to solving climate change and so have little leverage. And the lesser vulnerability of high emitters means that they are much more willing to accept suboptimal or non-solutions that protect their interests over optimal solutions that require real sacrifices on their part. So, in climate negotiations, high emitters are well-placed to bargain for greater concessions to their interests; they are more essential to the solution and less reliant on robust resolutions to satisfy their interests. Second, high emitters have considerably greater power over low emitters. They are wealthier, possess greater military capabilities, possess soft power that can shape norms and attitudes, and have greater formal and informal status in global governance institutions. Thus, high emitting countries have vastly superior positions and wield considerable power over low-emitting nations.

High emitting nations have recently - through the Paris Agreement - taken marginal steps to create a mitigation regime that may, under quite optimistic assumptions about how the various requirements to mitigate will strengthen over time, prevent the world from jumping the 2-degree Celsius guardrail. Yet, even granting that optimistic view, the 2-degree limitation will not prevent all seriously negative impacts to countries like Oceania. So, we have the question of what countries that will suffer deeply yet will not be compensated, either due to the lack of political will or because the wrong is not compensable (as the loss of one's homeland may be), ought to do. Second, even if we grant the Paris Agreement and its later specifications will go far in achieving a more just environmental regime, it still represents the decision by the powerful for the weak. The international order lacks the adjudicative, legislative, or executive 
mechanisms that will allow a very small, weak, or poor country to hold large, powerful, and rich countries to account. There are no global elections, no sovereign international law, or climate courts that might meaningfully constrain powerful actors. Of course, powerful states might be constrained by their own opinio juris - their own view that a particular international law is binding - or by coalitions of other powerful states coordinated around norms or formal institutions. Norms can even be changed through the actions of activists (Finnemore and Sikkink, 1998). But in each case, powerful states either constrain themselves or are structured by other powerful actors. The mechanisms that ensure that the interests of the weak and marginalized are taken into account are nonexistent, inchoate, or ineffectual. ${ }^{10}$

\section{Geoengineering as Civil Disobedience}

Climate change will cause substantial negative impacts on innocent parties, SAIs can reduce some of these impacts while causing other negative consequences, and climate change evinces a set of deeply problematic political relations. So, let us return to Oceania. SAIs cannot be justified as an act of self-defense. However, we need not conceptualize SAIs as an act of self-defense. Rather, SAIs might be justified as a revolutionary act designed to alter global political relations in a non-dominating direction. In order to understand this view, it is important to compare it to a similar, yet subtly different and inferior conception ${ }^{11}$ : geoengineering as civil disobedience.

Some have recently suggested that a country like Oceania could engage in SRM as an act of global civil disobedience (Morton, 2015). By so flagrantly violating the norms of climate change governance and engaging in such an obviously risky and desperate action, Oceania could force the hand of the rest of the international community and pressure them to adopt a more robust mitigation regime. In a sense, Oceania's action could shame powerful, high-emitters into

10 It is fair to point out that these arguments are somewhat sketchy. For a fuller analysis, please see Smith (2020, 2019, and 2015) Additionally, I present three responses. First, if one does not share my view of the global order, then one can present this view as a conditional. If the global order does not prevent domination, then global revolutionary action in the form of geoengineering may be permissible. Second, it should be noted that republican theorists - of a variety of schools - share my low opinion of the current order. See, on the neo-republican interpretation, Cécile Laborde (2010) For the Kantian interpretation, see Louis-Philippe Hodgson (2012). Third, one of the key features of climate change is its temporal nature. Preventing dangerous climate change will - given the size of the economies and changes to be made - will require almost immediate, large-scale action. That time pressure makes it especially difficult for the international community to respond effectively and adequately.

11 Similar objections can be raised to accounts of international rule-breaking and rule-making (Robert Goodin, 2005; Buchanan, 2001). Besides the issues associated with the 'civil disobedience' model as applied to law-breaking as lawmaking, a major issue with applying these accounts to SAIs is that SAIs are not illegal (Reynolds, 2016). The problem with SAIs is not that their use undermines the rule of law but that they violate basic entitlements. Revolution is meant to represent an emergency solution to a moral dilemma or tragedy, Buchanan and Goodin are offering accounts for the accretive improvement of the law. Finally, Goodin and Buchanan depend upon multiple instances law-breaking in order to create a new customary norm, I rely on a one-off deployment creating a new negotiating equilibrium. The views have structural similarities but remain quite different. 
changing their behavior and coordinating more effectively around the kind of mitigation regime that is needed in the long term. And we can readily imagine that the people of Oceania could satisfy many of the standard conditions of civil disobedience such as sincerity and conscientiousness in their desire to open the eyes of the world to a moral catastrophe. The action would be both relevantly political and - at least eventually - public. Of course, the initial SAIs would likely need to be done in secret, but it is normally acceptable to use secrecy to get into position to engage in civil disobedience as long as the violation of the law is done in public.

Yet, there are serious problems with understanding geoengineering as civil disobedience. The most important of these obstacles is that civil disobedience normally involves the direct or indirect violation of a law that protects unjust entitlements. ${ }^{12}$ For example, when members of the Southern Christian Leadership Coalition engaged in direct action against segregated lunch counters in downtown Nashville, they were violating the legal entitlements that the diner and mall owners had to segregate if they wished. Yet, these are not weighty moral entitlements. So, the primary negative consideration that the civil disobedient must overcome is the general value of the rule of law and the importance of being able to structure one's life around the kind of reliable expectations made possible by an effective though imperfectly just legal system. The potential wrong of civil disobedience is generated not by individuals who will suffer particular legal violations or economic costs (one of the main reasons the Nashville lunch counter protests worked is that they drove away customers and put economic pressure on downtown malls that primarily catered to African-American clients) but rather by the claims of the community for a reliable rule of law. This gives rise to the most distinctive element of civil disobedience: a public commitment to accept the punishment that normally attends the breaking of the law. ${ }^{13}$ By accepting the punishment, the civil disobedient does two things. First, they undermine the negative effects - precedential and otherwise - of their actions on the rule of law by placing their transgression in the context of the normal operation of the legal system. Second, the willingness to accept punishment expresses the civil disobedient's commitment to the equality of one's fellow citizens, communicating that they do not view themselves as above the law or deserving of special treatment.

Two elements of Oceania's SAIs deployment block this strategy. First, the international system lacks the legal structure necessary for civil disobedience.

12 See MLK's 'Letter from a Birmingham Jail' as paradigmatic, supplemented by Rawls (1971) and Brownlee (2007).

13 Brownlee, for example, has argued that punishment-acceptance is not a necessary feature of civil disobedience. While this might block the conceptual worry about OCEANIA's willingness to accept punishment, it would leave the other argument about how civil disobedience becomes less attractive as it undermines the legitimate entitlements of victims untouched. 
Even if Oceania was willing to accept punishment - and ex hypothesi, it is not - the international legal order is not positioned to reliably and publicly adjudicate the relevant punishment. In other words, the international legal order is not sufficiently well-structured - with well-defined statutes and expected punishment - for states to engage in paradigmatic civil disobedience. What's more, the international legal order allows - on a consistent basis - states to avoid or fail to comply binding legal norms without punishment. Since public and adjudicated punishment is not in the typical profile of non-compliance with international norms, acceptance of punishment cannot play a role in justifying a particular transgression. Second, the negative consequences of SAIs will be a deliberate and intentional violation of legitimate entitlements and not merely the undermining of global rule of law. Precipitation patterns will be disrupted, affecting food and water security in ways that people can reasonably claim should not be affected. Thus, it is unclear that a willingness to accept punishment can have the same expressive content or communicate the relevant sort of respect. So, the severity and urgency of the rights that will be violated by SAI deployment preclude Oceania from characterizing its transgressive geoengineering as civil disobedience.

\section{Global Revolution and Geoengineering}

Any attempt to justify Oceania's geoengineering must grapple with the fact that doing so will involve the intentional redirection of the threat of climate change onto vulnerable innocent people, thus violating their legitimate and welljustified entitlements to physical and economic security. ${ }^{14}$ I want to suggest that each of the prior failed views contain elements that - when placed in the context of global revolution - play a role in potentially justifying Oceania's geoengineering. The right to self-defense is important because it represents a model of how a threat can justify actions that would normally be unacceptable. That is, the right to self-defense - and just war theory more broadly - models how extraordinary, non-ideal behavior can nonetheless be constrained. Civil disobedience emphasizes the public nature of the norm transgression and the requirement that those who violate the relevant norm satisfy certain 'internal' criteria - they must be sincere and conscientious - in order for the action to be justified. Furthermore, civil disobedience emphasizes that the point of the particular transgression is not merely to resolve a particular injustice but rather to bring attention to and repair a broader set of moral and political issues.

14 There are, perhaps, other ways to frame this analysis. We could understand revolution as a 'supreme emergency' where we set ordinary morality aside or simply as 'violent civil disobedience.' The goal of the analysis is to show that 'revolution,' with its focus on institutional change, an attendant notion of moral risk, and the admixture of requirements setting it between self-defense and civil disobedience is a better, more productive concept than either of the above. 
The lunch counter sit-ins were about more than unjust policies in a particular restaurant. What's more, civil disobedience models a complicated justificatory structure where the law-breakers need to satisfy both internal and external conditions. While civil disobedience emphasizes the internal perspective of the disobedient, it also requires that the actions of law-breakers have certain or highly likely consequences, independent of whether they have those attitudes.

I want to suggest that revolution is a response to a particular type of moral tragedy. That is, revolution is justified when it is the appropriate response to a particular kind of normative problem. Revolution, as I define it, involves collective political action in transgression of well-justified political norms and principles and is aimed at changing, eliminating, or reforming fundamental political, economic, or social relations. Yet, what makes revolution a morally interesting category, as opposed to a political one, is that revolutions - like a more extreme kind of civil disobedience - generally require the transgression of legitimate entitlements. Since they demand the restructuring of fundamental political relationships, they relax the assurance that individuals have over whether their legitimate claims will be respected. This is what makes a revolution different and more morally risky than that of large scale social reform through legitimate processes: non-revolutionary change can still occur on a large scale and remake society but it operates through channels that respect existing entitlements. In fact, a set of evolutionary, lawful changes may have a greater effect on society than a set of revolutionary ones. Thus, what makes a set of changes revolutionary is its normative structure and not necessarily its size or influence. It is a willingness to set aside the ordinary and to claim that a set of radically new normative constraints and principles apply even if one grants that the prior order had at least some moral claims that are worth respecting. The tragedy is generated by a difficult combination: the status quo is morally unacceptable and permissible avenues of reform are unavailable. The moral tragedy, then, occurs when a set of political relations are structured such that they are egregiously unjust but that they can only be repaired or replaced through political means that violate the legitimate entitlements of others. Remaining in the current set of relations is wrongful but there is no rightful path for moving from our unjust present to at least a minimally acceptable future.

I want to treat 'revolution' as a constructed, functional concept where the conception answers a particular normative question: how ought we behave and demonstrate fealty to the values and rights we take to be important - when 
faced with this kind of political-moral tragedy? ${ }^{15}$ Justified revolutions are those that satisfy a particular conception of how to respect the claims of justice in a context where justice cannot be done. Unjustified revolutions are those that in either practice or effect - fail to respect those claims, even in the breach. The key point is that what makes a specific act revolutionary is not that it, all by itself, systematically changes the relevant social relations but whether violation of a well-justified entitlement plays a key role in the restructuring of those relations. Revolutions can proceed by stages and each stage may be quite different in terms of its legality and morality. If what would be a typically legitimate set of legislative actions - which themselves have large consequences - is only made possible by an initially unjustified, revolutionary seizure of power, then we should understand the complete set as revolutionary until some kind of normalizing or constitutionalizing process occurs. Revolutions are complex and ongoing processes. ${ }^{16}$

Oceania's dilemma is set in a revolutionary context. The current order is normatively unacceptable. The state will soon be destroyed by an environmental disaster not of its own making and that is generated by domination. Nondomination requires mechanisms of accountability and equal control. Unfortunately, those mechanisms do not exist in the international realm and, consequently, no non-dominating reform avenues exist, especially given the time constraints generated by the need to mitigate. Even if high emitting countries were to change their emissions behavior, they would still be dominating Oceania (Smith 2015, 2020).

The converse, however, is also true. If all geoengineering does is prevent the negative impacts of climate change, then Oceania cannot claim - on the basis of justified revolution - that it may geoengineer; it would simply recapitulate the problems of the self-defense argument. Justifying geoengineering as an act of revolution requires appealing to the greater political consequences of the action. As I have argued, these relations are wrongful because, at least in part, they are dominating, which does not stop simply because the dominus does not actually harm its subjects. So, something more than the mere avoidance of bad consequences must be true about geoengineering before we can claim that it resolves domination. Just as actions by high emitters that mitigate climate change do not necessarily change the dominating relations; actions by low emitters that allow them to negotiate or prevent the bad consequences of global,

15 See Caney's (2015, 63-64) global right to resist; in egregiously non-ideal circumstances, is there a middle ground between acting as if the world is ideal or acting in a purely instrumental fashion? However, unlike Caney, I am discussing far more radical and risky forms of resistance. For my analysis of the dynamics of domestic revolutions, please see Smith (2018).

16 The classic analysis of revolutions as a set of linked stages is found in Skocpol (1979). 
environmental domination do not necessarily make them less dominated. Thus, we have a key element of geoengineering as revolution that links it with the accounts of civil disobedience: revolutionary geoengineering must aim at repairing, replacing, or reforming the dominating, global relations that obtain between Oceania and the high-emitting powers that are primarily responsible for climate change. It is important to note that no particular revolutionary action need try to resolve all aspects of global domination; no revolution has ever holistically resolved all of the injustices of a particular community. Rather, the claim is that a successful revolution aims at changing power relations at a more fundamental level than merely attempting to resolve a particular injustice or harm. How broad or holistic a revolution must be will depend upon a multitude of factors, including both how risky and dangerous the revolutionary action will be and the potential benefits of the revolutionary action. In other words, the revolutionary action is justified by appeal to a set of institutional reforms that can properly compensate-in the long term-for the harms of the revolution.

A justified, revolutionary act of geoengineering by Oceania must aim at making progress towards the reform of global domination. Yet, how should the justification and the consequences of the action be related? There are many possibilities. For example, we might think that revolution is justified if those who engage in it reasonably believe that they are contributing to the end of global domination. A revolution could be justified, on this view, even though it failed to change political relations at all. In the other direction, a revolution could be justified only insofar as it in fact resolved or reformed the relevantly unjust political relations. That is, a revolution is only justified if it is successful regardless of the intentions or beliefs of the revolutionaries. There are, obviously, intermediate views that would require that the revolution have at least a certain probability of success, perhaps combined with the requirement that the revolutionaries have beliefs that non-accidentally correspond to those probabilities.

I wish to defend a full success condition for justified revolution. Call the success condition the externalist requirement on the revolutionary vanguard. So, if a revolution fails to contribute to the resolution of wrongful political relations or does so too weakly, then it is unjustified even if the revolutionaries reasonably expected it to succeed or there was an objectively high likelihood of success. Why such a stringent, externalist standard for justification? I offer two related reasons for the claim. First, we saw that one of the key elements of an account of revolution is that it must take seriously the idea that revolutionaries will violate the legitimate and morally well-justified entitlements of others. So, there needs to be some acknowledgement, within the account, that this is not 
an ordinary moral act, that it represents a kind of moral risk, an extraordinary rupture with day-to-day morality. Revolutionaries violate moral boundaries with the hope that their new order will do better. It is not implausible that the concrete benefits may be able to override or compensate for the costs of the violation. What seems far less plausible is that the unfulfilled expectation of improvements in the world can compensate or override rights violations. It should be noted that externalist conditions in cognate accounts like just war theory are nothing new. Military attack must actually be necessary, last resort and proportionate for the attack to be justified (the blameworthiness or criminal liability of combatants is a different issue). Unlike the objects of justified actions of self-defense, the victims of revolutionaries have not forfeited their rights. What's more, unlike the 'collateral damage' of a military attack, revolutions are necessary in part because nothing but actions that violate rights will reform an egregiously unjust system. In that context, you take on a moral risk: if you succeed, then what you did might be justified insofar as you do enough good. If you fail, then the rights violations were simply wrong and a variety of negative consequences might follow.

The second reason for adopting the success condition is that it makes sense of rightful resistance to revolution. Revolutions are morally fraught because loyalists are often justified in their resistance and victims of revolutions in their resentment. If revolutionaries were justified at the moment they decided to revolt because they met lower standards of success, it would be difficult to make sense of the idea that loyalists and revolutionaries could be justified in their opposing reactions. The way to solve the problem is to suggest that each side is justified at different points in time. The loyalists who act to prevent the revolutionary rights violations are not wrong to do so and the resentment by the victims is justified, but once the revolutionaries win and then succeed in improving the relevant set of political, social, and economic relations, loyalists are not then justified in resisting the new political order. At that point, the revolutionaries become justified in their actions and so political resistance to the new order cannot be justified on those grounds. ${ }^{17}$ However, if the revolutionaries fail, then their punishment or the negative consequences they suffer in virtue of effective, loyalist resistance is not wrong. By attaching a success condition to revolutions, we can create a temporally distinct set of revolutionary stages by which the moral justification of different actions by different actors changes in a way that more closely matches the normative complexity engendered by political actions that, by necessity, must violate people's rights.

17 I think this mimics a similar structure in Kant's account of revolution (Korsgaard, 1997). 
Satisfying the externalist condition, while necessary forjustifying revolutionary action, does not seem sufficient. After all, a strict interpretation of the success condition would imply that a rights-violating despot that happened to resolve some important injustice may therefore be a justified revolutionary. To forestall this possibility, revolutionaries need to express a commitment or a concern for the victims of their revolutionary action. Call this set of commitments the internalist conditions for justified revolution. Revolutionaries typically express this commitment by arguing that they are representatives of the relevant political community. That is, they claim-over and above the existing government or governments-to speak for the people, even those that are the victims of revolutionary violence. This claim reflects, under the right circumstances, a certain kind of respect for the victims by suggesting that they are part of the revolutionary coalition and that their interests are being considered.

Yet, this raises the question of what must revolutionaries do and believe in order to be the appropriate kind of representatives. At the very least, many of the standard requirements of civil disobedience apply. The revolutionaries must be conscientious, sincere, and transparent, explicitly and publicly committing themselves to the political resolution that would justify their actions. However, I argue that they must also be inclusive. So, if the revolutionary cadre is going to claim to represent the will of the people, then they cannot arbitrarily exclude classes of individuals from the revolutionarily coalition simply because those classes normally oppose the revolution. Take, for example, the French Revolution. The revolutionary coalition included aristocrats and clergy-and in the beginning, took their views and concerns seriously-and treated them as having a claim to justification and participation insofar as they endorsed a reasonable facsimile of the public commitments of the revolution. This need for inclusion is especially urgent if the costs of revolutionary violence will likely fall on a particular sector of the community, and a good faith effort to find representatives is key to the legitimacy of the movement. What's more, the decision-making processes within the movement must be inclusive in ways beyond membership. A revolutionary coalition that is dominated by a cult of personality or restricts true decision-making power to a secretive cabal would not be genuinely representative. This is particularly necessary if participants from the victimized class are especially likely to be excluded from positions of influence within the movement. Of course, the demands of inclusivity must also be balanced against the demands of effectiveness, cohesion, and operational security. This should not be read as a requirement that every movement have formal democratic congresses, though many successful revolutions have maintained surprisingly democratic political formations even in the face of dire 
threats. Rather, the vanguard must make good faith efforts and be willing to sacrifice some of their interests or effectiveness in order to be as inclusive as is feasible.

To sum up, a justified revolution is a complicated beast. A revolution becomes justified when it satisfies the success condition and the revolutionary movement satisfies theinternalist conditions concerning publicity, sincerity, and inclusivity. If all of those conditions are met, then revolutionaries might nonetheless be justified in performing actions that violate well-justified entitlements in ways that - under ideal conditions - would be deeply wrong.

\section{Geoengineering as Revolution}

We have already seen that Oceania has found itself in a revolutionary context. The current political order and the climate change consequences it has generated are unacceptable. Yet, there are no rightful means for repairing the order in time to avoid the climate change impacts that threaten the community with destruction. So, what needs to be true about Oceania's actions and decisionmaking for the revolutionary SAI to be justified?

Let's begin with the internalist conditions. First, the revolutionaries in Oceania must sincerely, publicly, and conscientiously aim at altering the wrongful political relations that obtain between climate change perpetrators and their victims. Second, the revolutionaries must be appropriately inclusive. The scope of that inclusivity is defined by those who will suffer from the effects of the revolutionary action. Again, it would be insufficient if Oceania was itself democratic, since the potential victims of their revolution are located beyond their borders. The revolutionary context is one where global political relations are wrongful and the aim of the revolutionary action is to repair those relations. So, in that sense, Oceania would need to represent the class of individuals that are globally dominated and show particular deference to the subset of individuals who will see their rights undermined by geoengineering. This means that Oceania will not be able to act unilaterally; it will need to generate formal or informal mechanisms that will allow other globally dominated agents or their representatives to participate in the decision-making process about the particulars of various geoengineering strategies and levels of deployment. $E x$ hypothesi, we have granted that Oceania is one of the few states that is rich enough to deploy geoengineering and yet is not a major contributor to climate change. As such, Oceania will need to be careful to avoid using its superior economic position to its victims to dominate the proceedings of the revolution, and its success in managing this diverse coalition in an equitable manner will play a large role in whether the action is justified. 
One way of expressing or demonstrating a commitment to the broader objectives and membership of the revolutionary coalition will lie in the details of the geoengineering deployment. There will likely be a large set of plausible geoengineering suites that will combine a diverse set of techniques, particles, injection levels, and injection sites. Different agents will benefit and suffer as a result of the selection of a particular suite (Nalam et al., 2017; MacMartin et al., 2018). Expressing a broad-based commitment to representing low-emitting countries dominated by current climate change policy would mean selecting a suite that is not solely committed to maximizing the interests of Oceania. The vanguard will need to select a geoengineering suite that involves a certain amount of sacrifice of its own interests in order to show its commitment to representing the victims of its revolutionary act. For example, Oceania might have the choice of SAIs that return global temperatures to a point where they will need to expend few resources to hold back the ocean through sea walls. Yet, this form of extreme geoengineering increases the likelihood and severity of the precipitation disruptions that violate the entitlements of low-emitters around the globe. A lesser intervention - where less material is injected or a more distant injection site is selected - would likely impose costs on Oceania either by making the injections more expensive or by forcing increased adaptation efforts. A revolutionary leadership that was unwilling to countenance sacrifices on its part in order to more equitably distribute the costs of their revolutionary transgression would fail to be inclusive.

To sum up, the revolutionaries will need to be publicly and sincerely committed to altering the relations of domination as they are instantiated in climate policy. They will need to create mechanisms for the inclusion of other dominated persons outside Oceania or their representatives, including and especially those who are likely to be victimized by Oceania's revolutionary action. Third, those mechanisms will need to be sufficiently robust such that Oceania's revolutionary leadership feels bound to sacrifice some of the interests of Oceania in order to reduce-or distribute more equitably-the negative consequences of their geoengineering.

We now turn to how Oceania's actions might meet the externalist conditions of justified revolution. Three points are worth noting. First, all I can demonstrate is that there are possible paths to resolving domination; many things might intervene to block those paths and, if that happens, then the revolution never becomes justified. Even if the revolution generates some good effects, we will need to weigh those effects against the costs of revolutionary action and that will rely on difficult and complex empirical judgments in order to ascribe negative impacts to the deployment of SAIs. Second, it is important to see 
that domination-as a relational concept-can be resolved for one relationship without being completely resolved for all others. Third, one can resolve domination by creating mechanisms of contestation or by equalizing power between agents.

First, take a narrower set of dominating relations: those between the high emitting nations and the people of Oceania. Geoengineering helps repair the dominating relations between the people of Oceania and those responsible for climate change by providing Oceania with the means of blocking a threat. We must remember that domination comes from a position of superior power and that the greater the power, the more intense the domination. One source of power is the ability to deploy threats and to demand concessions. Since climate change will be worse for low emitters, high emitters are in a superior position to demand and receive concessions in exchange for mitigation. However, the ability to block the impacts of climate change undermines the position of the high-emitters. Or, at least, it is reduced for the people of Oceania who would be desperate to accept any deal that would save their community. So, rather than having to beseech high emitters to change their behavior, the people of Oceania have a tool within their disposal that makes such pleading less necessary. This is the equivalent of peasants seizing land and deploying their new found entitlements to adopt a more favorable negotiating position in the labor market without greater institutional change. This revolutionary act reduces domination by equalizing power by giving those who are weak more effective tools for representing their own interests. And most importantly, these tools are under the control of the people of Oceania, to be used as they and their revolutionary comrades deem appropriate.

This strategy is twice limited. First, providing the weak superior tools without the accompanying systemic change will be insufficient to the task of repairing global inequalities. Second, geoengineering cannot replace mitigation in the long term. If no mitigation occurs, then we run the risk of termination shock where rapid increases in global temperature occur once the temperature suppressing radiative forcing of SAI is removed. In order to keep up with rising emissions, more and more sulphate would need to be injected, leading to greater and greater risks of failure or large-scale negative side effects. Yet, this leads to an overall increase of the position of low-emitters in relation to high emitters. Geoengineering by low-emitting countries has the potential to be a pre-commitment mechanism that forces high emitters to mitigate. How might this work? The essential thing to recall about the current situation is that the uneven distribution of benefits and burdens of climate change drives - at least in part - the specific dynamics of climate change domination. There are, of course, 
other components: procedural inequalities within the process of international adjudication as well as asymmetries in military and economic power. Yet, the specific features of climate change that make that arena especially dominating is the particular distribution of consequences of high-emitting behavior. In response, SAIs can represent a climate version of mutually assured destruction. While many high emitting countries can be expected to weather climate impacts that would be devastating to many low emitting countries, no country can adequately deal or prepare for the rapid temperature increases associated with termination shock. For example, many have argued that the United States and Canada can accept a 2.5 degree increase in global temperatures without suffering net ill effects (Posner and Weisbach, 2013, Chapter One). Yet, those studies assume a 2.5 degree increase over the course of a century or more. The rate of change is as important as the amount of change when it comes to adapting to climate change impacts: the same increase over a thousand years is much less daunting than over a decade. This significantly improves the negotiating position of the weaker, low-emitting countries as they can control when to stop injecting. If the high emitting countries want to avoid termination shock, then they will need to mitigate.

A mitigation regime that simply relies upon the goodwill of the high emitters will be a dominating one. A non-dominating regime is one where the distribution of power and checks within the system is sufficiently structured and balanced such that the weak can hold the strong accountable. Absent a common power controlled by all, any non-dominating (or less dominating) global regime must be undergirded by structures of material power that are equitable. This is, perhaps, impossible to fully achieve in climate change. However, we can take concrete steps in the direction of supporting a regime that will take the interests of low emitters into account with material incentives that pressure the powerful. So, geoengineering may not only - through civil disobedience and law-breaking - generate new norms and institutions but also may change power structures in a way beneficial to low emitters. Once mitigation takes hold, I have argued elsewhere (Smith, 2013) that there are good reasons to think that the material incentives will - eventually - create a positive spiral whereby low-carbon economies will generate their own material incentives towards sustainability. What is needed is a 'sharp knock' that changes power dynamics that allow the high emitters to ignore the interests of low emitters. Revolutions create the conditions for more permanent reform; as Robespierre said: 'The aim of constitutional government is to preserve the Republic; that of revolutionary government is to lay its foundation.' The development, threat, and deployment of SAI provides weaker states with a greater bargaining position to create a 
public mitigation and adaptation regime that more equitably represents their interests and generates material changes in power relations to hold high emitters accountable for their behavior. Of course, the creation of this next regime is, at the moment, speculative. As a result, we cannot be sure such revolutionary actions will be justified.

One might object ${ }^{18}$ at this point that SAIs are not particularly revolutionary because they do not attack the systemic underpinnings of global inequality; rather, they represent a risky strategy for achieving non-domination only in the context of climate change and its response. There is something to this; after all, I am suggesting that the revolutionary objective for Oceania is an equitable and accountable mitigation and adaptation regime based on somewhat equalized power relations. This regime would leave many sources of global inequality untouched and that seems hardly revolutionary. Further, SAIs do not seem like an especially promising revolutionary strategy for addressing the more systemic sources of global inequality and oppression. There are two responses to this worry. First, climate change is not as contextually narrow as it might appear. Responding to climate change in an equitable fashion will almost certainly lead to improvements in other domains of global inequality. Responding to climate change will require resilient economic development, and an equitable mitigation regime would represent a substantial transfer of wealth and power from the strong to the weak in the context of an urgent global issue. This is to say nothing of the way that an effective and equitable mitigation regime would change the way we relate to the environment and to future generations. So, insofar as SAI represents a risky, collective attempt to uproot the existing power structure concerning the management of the global atmospheric commons and replace it with a regime that transfers wealth and power to those who have previously been subject to domination, it does not strike me as inappropriate to describe that potential change as revolutionary. Second, revolutions-at least those political movements, periods, and actions described as revolutionary in our political culture-frequently have narrow political goals that lead to unintended, broader social effects. These revolutionaries are concerned with a specific set of social, political, or economic relations with either an indifference or an outright desire to keep other relations the same. Moreover, the use of 'revolution' in international affairs is very narrow; revolutions often merely refer to the replacement of one hegemon by another (Halliday, 1990). So, I do not believe my use of revolution-even if it is a regimented definition-is widely out of step with ordinary usage. The Oceanians are engaged in a presumptively wrongful and dangerous attempt to restructure unjust power relations in order to make them more equitable in a context of an issue of immense important.

18 I thank an anonymous reviewer for pushing me to engage with this worry. 
This is, of course, an immensely risky strategy. Not only is there no guarantee it will work, it is difficult to make judgments even concerning how likely it is to succeed. Under normal circumstances, we should adopt a precautionary approach and stay away from SRM strategies. Yet, Oceania is not faced with ordinary circumstances. Those who would resist Oceania or reject the revolution would not necessarily be acting wrongfully. One of the many tragedies of egregious injustice and of revolution is that virtuous people can find themselves on opposite sides. Like all revolutionaries, the people of Oceania might need to take a leap into the unknown. It is a sign of the moral urgency-and the depth of our collective moral failure-of climate change that such actions need to be contemplated. Yet, many revolutionaries have taken similar risks under similarly desperate circumstances, and we have come to view them as heroes and exemplars. ${ }^{19}$

Patrick Taylor Smith

Assistant Professor

Department of Philosophy

University of Twente

email:p.t.smith@utwente.nl

\section{the global justicenetwork}

19 I would like to thank several anonymous reviewers as well as Brian Berkey for their extensive comments. I would also like to thank the participants of the Rabinowitz Symposium on Climate Ethics at the University of Washington, Seattle, the 4TU Ethics Conference at Eindhoven, the Philosophy and Social Science Conference in Prague, the Braga Meetings on Social and Political Philosophy, and the Rocky Mountain Ethics Congress for their patient and productive thoughts on various versions of this paper. 


\section{References}

Althor G, Watson, James E. M. and Fuller, Richard A (2016) Global Mismatch between Greenhouse Gas Emissions and the Burden of Climate Change. Scientific Reports 6, 20281.

Blomfield M (2015) Climate Change the Moral Significance of Historical Injustice in Natural Resource Governance. In: McKinnon C and Maltais A (eds) The Ethics of Climate Governance. Rowman and Littlefield.

Brownlee K (2007). The Communicative Aspects of Civil Disobedience and Lawful Punishment. Criminal Law and Philosophy 1: 179-192.

Buchanan A (2013) The Ethics of Revolution and Its Implications for the Ethics of Intervention. Philosophy and Public Affairs 41 (4): 291-323.

Buchanan A (2001) From Nuremberg to Kosovo: The Morality of International Legal Reform. Ethics 111: 673-705.

Caney S (2015) Responding to Global Injustice. Social Philosophy and Policy 32 (1): 52-73.

Carson, Clayborne (ed) (2001) The Autobiography of Martin Luther King, Jr. Grand Central Publishing.

Corner A and Pidgeon N (2010) Geoengineering the Climate: The Social and Ethical Implications. Environment: Science and Policy for Sustainable Development 52: 24-37.

Ferraro A, Charlton-Perez, AJ and Highwood, EJ (2014) A Risk-Based Framework for Assessing the Effectiveness of Stratospheric Aerosol Geoengineering. PLoS One 9(2): e88849.

Finnemore M and Sikkink K (1998) International Norm Dynamics and Political Change. International Organization 52: 887-917.

Fruh K and Hedahl M (2019) Climate Change is Unjust War: Geoengineering and the Rising Tides of War. The Southern Journal of Philosophy 57(3): 378-401.

Gardiner S (2012) The Desperation Argument for Geoengineering. PS: Political Science and Politics 46: 28-33.

Gardiner S (2011) Is 'Arming the Future' with Geoengineering Really the Lesser Evil? Some Doubts About the Ethics of Intentionally Manipulating the Climate System. In: Gardiner S, Jamieson D, and Shue H (eds) Climate Ethics: Essential Readings. Oxford: Oxford University Press.

Goodin R (2005) Towards and International Rule of Law: Distinguishing International Law Breakers from Would Be Law Makers. Journal of Ethics 9: 225-246.

Halliday F (1990) 'The Sixth Great Power': On the Study of Revolution and International Relations. Review of International Affairs 16: 207-221.

Hodgson L-P (2012) Realizing External Freedom: The Kantian Argument for a World State. In: Ellis E (ed), Kant's Political Theory. University Park: Penn State University Press: 101-34. 
IPCC, 2014: Climate Change 2014: Synthesis Report. Contribution of Working Groups I, II and III to the Fifth Assessment Report of the Intergovernmental Panel on Climate Change [Core Writing Team, R.K. Pachauri and L.A. Meyer (eds.)]. IPCC, Geneva, Switzerland.

Jamieson D (2005) Adaptation, Mitigation, and Justice. In: Sinott-Armstrong and Howarth R (eds) Perspectives on Climate Change: Science, Economics, Politics, and Ethics. Advances in the Economics of Environmental Resources.

Keith D (2013) A Case for Climate Engineering. Boston: MIT Press.

King ML (1994) Letter from a Birmingham Jail. Harper: San Francisco.

Korsgaard C (2008) Taking the Law into Our Own Hands: Kant on the Right to Revolution. In: Reath A, Herman B, and Korsgaard C (eds) Reclaiming the History of Ethics. Cambridge: Cambridge University Press.

Laborde C (2010) Republicanism and Global Justice. European Journal of Political Theory 9: 48-69.

Long, Huey ()1973). Revolutionary Suicide. Manhattan: Random House.

MacMartin, D (2018) Solar Geoengineering as Part of an Overall Strategy for Meeting the $1.5^{\circ} \mathrm{C}$ Paris target. Philosophical Transactions of the Royal Society A: A Mathematical, Physics, and Engineering Sciences 376 (2119).

McMahan J (2004) The Ethics of Killing in War. Ethics 114: 693-733.

Morrow D (2014) Ethical Aspects of the Mitigation Obstruction Argument Against Climate Engineering Research. Philosophical Transactions of the Royal Society 372.

Morton O (2015) The Planet Remade: How Geoengineering Could Change the World. Princeton: Princeton University Press.

Nalam A, Govindasamy, B and Modak, A (2018) Effects of Arctic Geoengineering on Precipitation in the Tropical Monsoon Regions. Climate Dynamics 50: 3375-3395.

Pettit P (1997) Republicanism: A Theory of Freedom and Government. Oxford: Oxford University Press.

Rawls J (1971) A Theory of Justice. Cambridge: Harvard University Press.

Reynolds J (2016) Climate Engineering, Law, and Regulation. In: Brownsword R et al. (eds) The Oxford Handbook on the Law and Regulation of Technology. Oxford University Press.

Ripstein A (2009) Force and Freedom: Kant's Legal and Political Philosophy. Cambridge: Harvard University Press.

Shue H (1993) Subsistence Emissions and Luxury Emissions. Law and Policy 15 (1): 39-60.

Sillmann J et al. (2015) Climate Emergencies Do Not Justify Engineering the Climate. Nature Climate Change 5 (4): 290-292.

Skocpol T (1979) States and Social Revolutions. Cambridge: Cambridge University Press.

Smith PT (2018) Political Revolution as Moral Risk. The Monist 101(2): 199-215. 
Smith PT (2012) Domination and the Ethics of the Geoengineering. In: Preston C (ed) Engineering the Climate: The Ethics of Solar Radiation Management. New York: Lexington Books.

Smith PT (2013) The Intergenerational Storm: Dilemma or Domination. Philosophy and Public Issues 3(1): 207-244.

Smith PT (2014) Redirecting threats, the Doctrine of Doing and Allowing Ethics, Policy, and the Environment 17(2): 143-146.

Smith PT (2015) Domination and a Global Emissions Regime. In: McKinnon C and Maltais A (eds) The Ethics of Climate Governance. Rowman and Littlefield.

Smith PT (2019) Legitimacy and Non-Domination in Solar Radiation Management Research. Ethics, Policy, and the Environment 21(3): 341-361.

Smith PT (2020) A Normative Foundation for Statism. Critical Review of International Social and Political Philosophy: 532-553.

Tuana N et al. (2011) Sulfate Aerosol Geoengineering: The Question of Justice. Public Affairs Quarterly 25: 157-180.

Vanderheiden S (2008) Atmospheric Justice. Oxford: Oxford University Press.

Walzer M (2000) Just and Unjust Wars. New York: Basic Books.

Weisbach D and Posner E (2013) Climate Change Justice. Princeton: Princeton University Press. 